BULLETIN NO. 5.

U. S. DEPARTMENT OF AGRICULTURE. DIVISION OF POMOLOGY.

\title{
FIG CULTURE.
}

\section{EDIBLE FIGS: THEIR CULTURE AND CURING.}

\section{By GUSTAV EISEN,}

Curator in Biology, California Academy of Sciences; San Francisco, Cal.

\section{FIG CULTURE IN THE GULF STATES.}

By FRANK S. EARLE,

Horticulturist, Alabama Experiment Station, Auburn, Ala.

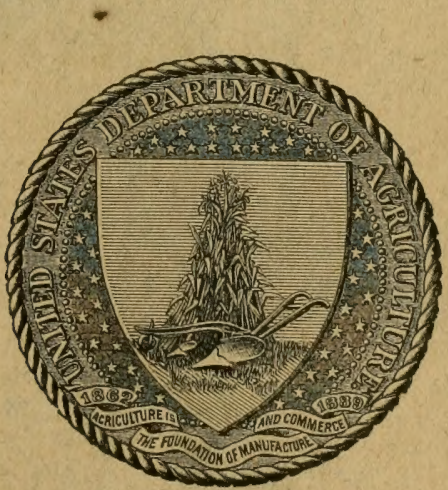

WA SH I N GTON:

GOVERNMENT PRINTING OFFICE. I 897 . 


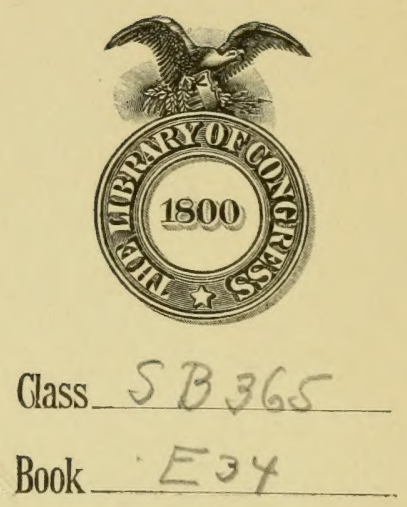





BULLETIN NO. 5 .

\title{
U. S. DEPARTMENT OF AGRICULTURE.
}

DIVISION OF POMOLOGY.

\section{FIG CULTURE.}

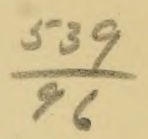

\section{EDIBLE FIGS: THEIR CULTURE AND CURING.}

\author{
By GUSTAV EISEN,
}

Curator in Biology, California Academy of Sciences,

San Francisco, Cal.

- FIG CULTURE IN THE GULF STATES.

\section{By FRANK $S /$ EARLE, $_{10}$}

Horticulturist, Alabama Experiment Station, Auburn, Ala.
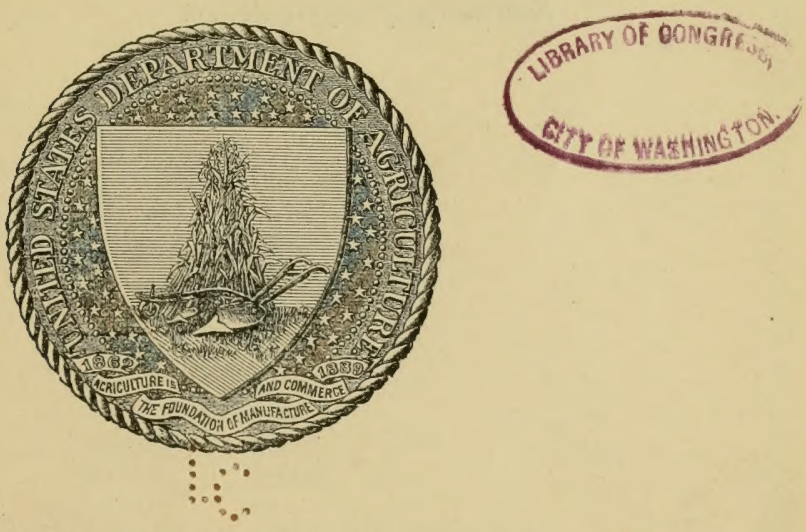

WA SH I N GTON:

GOVERNMENT PRINTING OFFICE.

I 897 . 


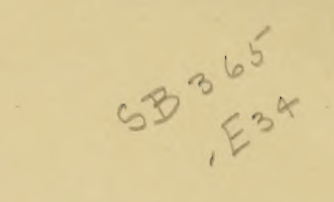

\section{LETTER OF TRANSMITTAL.}

\section{U. S. Departient of Agriculture, Division of Pomologr, Washington, D. C., January 30, $189 \%$.}

SIR: I have the honor to transmit herewith, and to recommend for publication as a bulletin of this division, articles on "Edible figs: their culture and curing," by Dr. Gustav Eisen, of San Francisco, Cal., and "Fig culture in the Gulf States," by Frank S. Earle, of Auburn, Ala. The climatic conditions of the sections of the United States in which figs can be successfully grown are so widely different that it has been deemed advisable to publish these papers as one bulletin, in order that a comprehensive presentation of the subject may be within reach of those interested in this industry.

Hon. J. Sterling Morton, S. B. Heiges, Pomologist.

$$
\text { Secretary of Agriculture. }
$$




\section{CONTENTS.}

Edible Figs: Their Culture and Curing. (By Gustav Eisen.)

Nature and structure of the flowers and fruit of the fig..............

Classification of varieties of edible figs

arieties of figs found useful in California. . . . . . . . . . . . . . . . . . 7

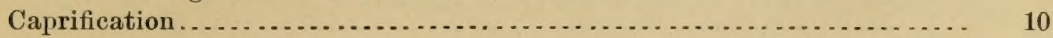

Climate suitable for fig culture ... . . . . . . . . . . . . . . . . . . . . . . . 10

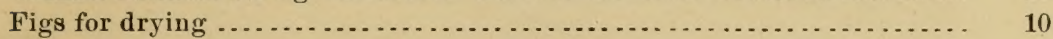

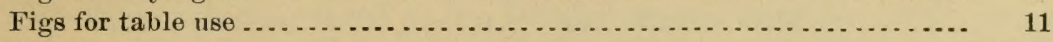

Figs for preserving, canning, and home consumption $\ldots \ldots \ldots \ldots \ldots \ldots . . . . . .11$

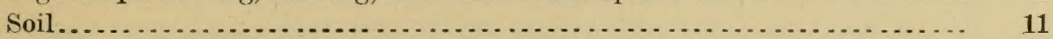

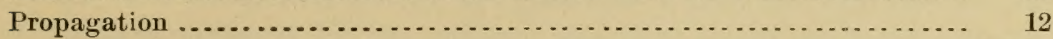

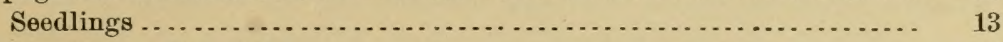

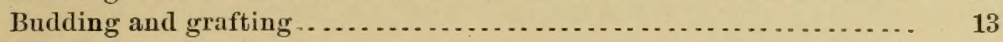

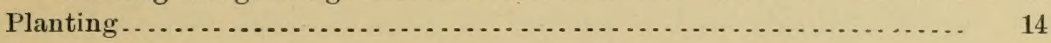

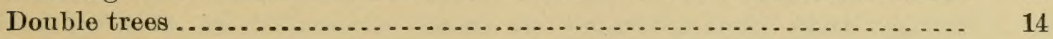

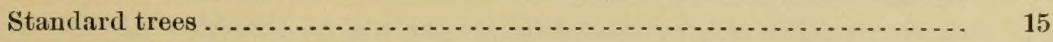

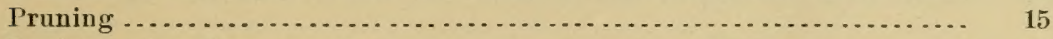

Drying and curing ........

Picking................................................... 16

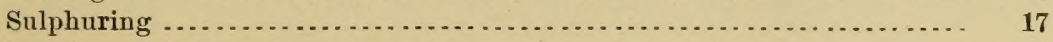

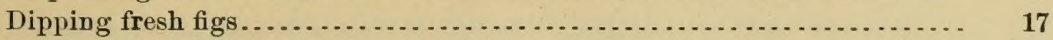

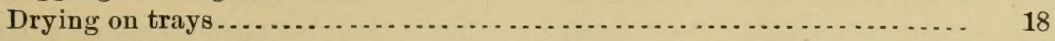

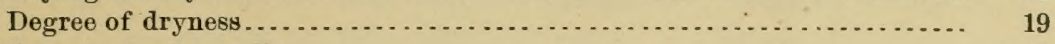

Sweating and equalizing . . . . . . . . . . . . . . . . . . . . . . . . . . 19

Artificial drying .............................................. 19

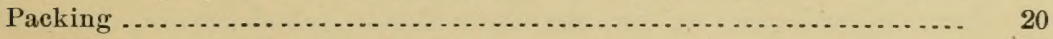

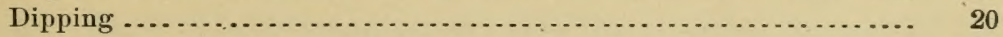

Assorting . . . . . . . . . . . . . .

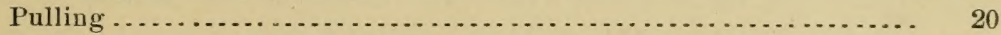

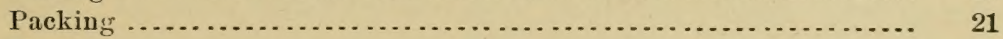

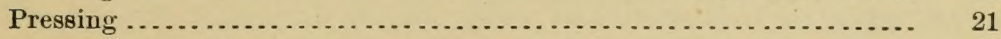

Fig Culture in the Gulf States. (By Frank S. Earle.) .............. 23

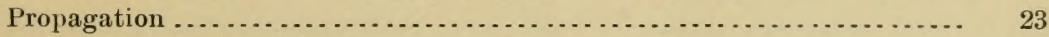

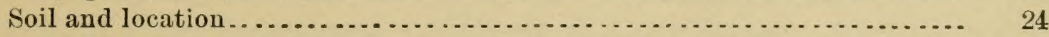

Cultivation and fertilization . . . . . . . . . . . . . . . . . . . . . . . . .

Insect enemies and diseases . . . . . . . . . . . . . . . . . . . . . . . . . . .

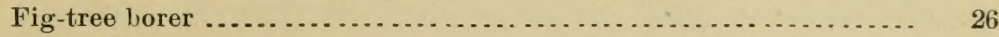

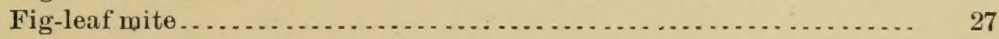

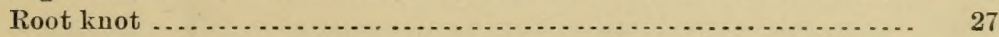

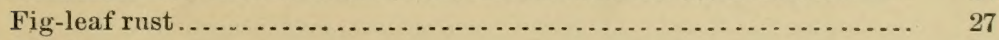

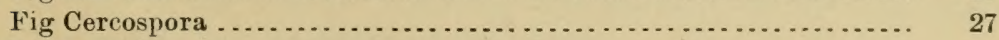

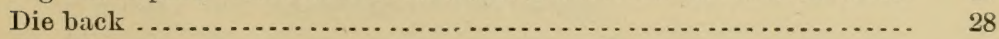

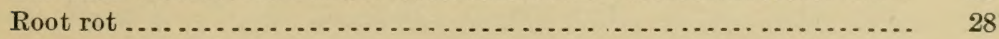

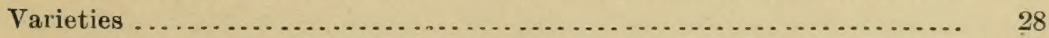

List of figs recommended by American Pomological Society ........ $\quad 29$

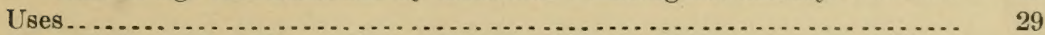

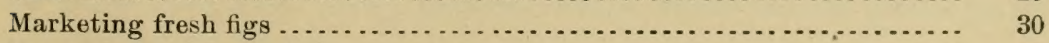

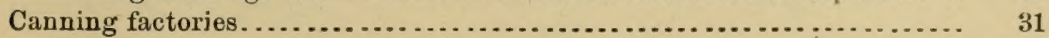





\section{FIG CULTURE.}

\section{EDIBLE FIGS : THEIR CLLTLRE AND CURING.}

By Gustay Eisen.

The edible figs cultivated in the United States both for eating fresh and for drying all belong to one species, Ficus carica. Of this species there are now described about 400 varieties which are sufficiently distinct to be considered by the student and the practical horticulturist. The intending planter should study the character of the varieties more closely than has hitherto been customary in this country, though his safest plan is, of course, to plant in quantity only such varieties as have proved valuable in his own locality, or where soil and climate are similar.

NATURE AND STRUCTURE OF THE FLOWERS AND FRUTT OF THE FIG.

Before we consider these different varieties, a few remarks on the nature and structure of the fruit are necessary. The fig which we eat is really a receptacle, on the surface of which are situated the numerous flowers. But as this surface is concave, or curved inwardly, like the hollow of a closed hand, the flowers can not be seen except when the fig is ent. Them it becomes apparent that the ehamber formed by the curved receptacle communicates with the ontside by means of the "eye" at its apex. In some varieties the "eye" is almost closed, opening only when the fig has reached a certain age; in others it is so large that a pea could easily pass through. The flowers are always more or less fleshy, are generally imperfect, and do not much resemble the bright flowers of other fruit trees and plants in our gardens. There are four distinct kinds of fig flowers, but these are not always found in a single fig, in fact they are rarely all found together. They are designated as follows:

Wale flowers. - These possess four pollen-producing stamens. They are found only in the wild or "capritig," the ancestor of our eultivated figs, and in a very few varieties of edible figs.

Female flowers.-These possess a single style, stigma, and ovary, and when fertilized, produce seeds. Owing to the absence of male flowers, or the failure of the male and female flowers in the same fig to mature at the same time, they rarely produce fertile seeds unless fertilized by pollen carried by insects. 
Gall fowers.-These are degenerate female flowers which do not produce seeds, the abortive ovary serving only for the habitation and breeding place of a very small wasp, the Blastophaga, which is used in caprification. The gall flowers are found only in the original wild fig.

Mule flowers.-These are imperfect female flowers, incapable of producing seeds or of affording a breeding place for the wasp. These flowers are found to the exclusion of all others in most of our cultivated figs.

Because of these differences in the flowers the numerous varieties of edible figs may be divided into tribes or subspecies. These are as follows:

\section{CLASSIFICATION OF VARIETIES OF EDIBLE FIGS.}

Caprifigs (goat figs or wild figs).-These figs grow wild in southern Europe, northern Africa, and western Asia, and have been recently introduced into California. They bear all the kinds of flowers except the mule flowers, and as they are the only figs bearing male flowers they are essential in all fig districts where mature and fertile seeds are of importance, or in other words, where caprification is necessary.

Smyrna figs.-These are grown only in the Smyrna district of Asia Minor. They have only female flowers, and neither these latter nor the receptacle on which they grow will come to any maturity without caprification or pollination. So-called Smyrua figs, which have been bought of nurserymen, have generally proved spurious, as, unlike the true Smyrna figs, they mature their fruit without pollination. Of late years true Smyrna figs have been planted in California, but they have failed to ripen fruit except when artificially pollinated. These will not produce ripe fruit in commercial quantities until eaprification ean be practiced, and neither these nor the caprifig shonld be planted at the present time, except for expermental purposes.

Common edible figs.-These are the common varieties of our orchards, which bear fruit and mature it with regularity without pollination or caprification. They bear two crops a year, the "early figs" or "brebas," and the later or "summer figs." Of this tribe alone there are some 400 varieties described more or less perfectly, and probably as many more undescribed and unknown.

San Pedro figs.-Whis tribe contains only a few dozen varieties, some of which are cultivated in California, and also in Florida and other Southern States. They are characterized by maturing only the first crop or "brebas." The second crop always drops before reaching maturity. The canse of this is that the first erop contains only "mule flowers," like those of the common figs, while the second contains only "female flowers," like those of the Smyrna figs.

The San Pedro tribe of fig varieties is specially valuable on account of the large size and early maturity of the "brebas" or first crop. They should, therefore, be planted only in places where it is desirable to grow large, early figs, for marketing fresh. They do not succeed everywhere, as they require a warm and early spring climate. 
In tropical countries there are numerous varieties of other species of figs growing wild. Many of them are edible, but all are less palatable than our edible fig, and with the exception of the Sycomore fig, Ficus sycomorus, of Africa, are of no economic importance except as food for animals.

For this purpose, however, they are very useful, and the Sycomore fig should be introdnced into the Southern States, where it would probably thrive in frost-free localities.

\section{VARIETIES OF FIGS FOUND USEFUL IN CALIFORNIA.}

The existing confusion regarding the names of the varieties of the fig is largely due to incomplete descriptions. The following points are of importance in every fig description, and should always be noted: Size, form, neck, stalk, ribs, eye, color of skin, color of pulp, seeds, quality, growth, and leaf. In order to simplify descriptions, these points should always be mentioned in the same order. It is also of great importance to note whether the first crop alone matures fruit, and whether the two crops differ materially in any of the above-mentioned points.

Of the 400 or more described varieties of figs, comparatively few have been tested in the United States. Most of those tested are French or hot-house varieties, very few southern or Mediterranean figs having been introduced, though many of the latter are worthy of testing in this country.

A few of the varieties that have been found most useful in California are described:

AdRIATIC.-Size medium, roundish; neck medium, stalk short; ribs obscure; eye open, with red iris; skin very thin, greenish in the shade, yellowish in the sun; pulp bright strawberry red or with violet streaks in the meat; varies in quality according to location.

This has been found rery useful in California, but is not of fine tlavor when dried. It requires rich soil, with considerable moisture and a very large percentage of lime. This variety is not identical with that known in Italy as Adriatic.

ANGELIQUE (syn. Angelica).-Medinm, pyriform; ribs prominent, yellowish white; pulp white with rose-colored center; leaves five-lobedi. A very good variety in some of the coast valleys.

ATIIENES(syn. Marseillaise).-CSmall, roundish or turbinate, with indistinct ribs, depressed at apex, skin rough; color whitish yellow, pulp reel, opaline; very sweet and one of the best drying figs both in France and California.

Bour.jassot'e, Buack (syn. Barnissotte, Black).-Merlium, broader than long, flattened at apex, with no neck and an uneven cheek; ribs distinet, even; eye small, sunk, elosed; skin waxy, black with violet blush; bloom clear blue, wanting at apex; meat pink, pulp blood-red. A most excellent fig for table. It requires rich, moist soil.

BourJassotte, WIITL: (syn. Bunissotte, White). - A fig related to the former, but larger; eye large, sunk; skin waxy, green; pulp bright red. A very fine fig. Tree very large. 
Brown TURKEY.-Large, turbinate, pyriform, with hardly distinct neck; stalk short; apex flattened; ribs few, slightly elevated; eye medium, slightly open, scales large; skin smooth, greenish to violetbrown in sun, with darker ribs; pulp dark, rosy red, quality good, and tree a good bearer. Brunswick is frequently confounded with this fig.

BRUNSWICK.-Very large, pyriform, with swollen cheeks, one of which is larger than the other; apex very obtuse; neck and stalk very short; ribs distinct, but not much elevated; eye medium, open ; skin pale amber with violet tint; pulp amber. An early, large fig, but with no flavor. Very common; requires rich, moist soil.

Celeste, Blue (syn. Violette).-Small, ovate, turbinate; ribs few, but distinct, especially near apex; eye raised, rough; color dark, violet amber, without reddish blush; bloom confined to the neck; skin thin; pulp deep rose; meat amber; sweet, but lacking in flavor.

Dоттато.-Medium ovate, pyrifom; neck well set; stalk very short or none; ribs low; skin smooth; eye medium; skin thin, yellowish green; meat white; pulp yellowish amber, sometimes with violet flush. One of the best figs for drying; tree a strong grower, requiring moist, rich soil. Lately introduced into California.

DraP D'OR.-Large, pyriform, with very low neck and stalk; ribs elevated; apex obtuse and concave; color light, violet, reddish amber, not dark; pulp rosy red. A fig of very fine quality, especially useful for confections and crystallizing; not identical with Brunswick.

DU Ror.-Above medium; round, pyriform; stalk very short; eye large or variable, with scales standing out; skin smooth, pale bluish green; pulp amber, with rosy streaks and exceedingly minute seeds. Related to Marseillaise and Athenes, and one of the very best figs in California for drying.

EARLY VIOLET.-Small to very small, round, turbinate; neck dis. tinct but short; stalk medium to long; ribs distinct, elevated, skin rough; violet-brown, with thin, pearl-colored bloom; pulp red. This variety bears almost continuously and is preferable to the Ischias and Celeste.

GENOA, WHITE.-Above medium, pyriform; neck small; stalk short; ribs indistinct; skin downy; eye very small; skin pale olive-green; pulp pale rose. One of the better figs, quite distinct from Marseillaise.

Gentile.-Very large; ovate pyriform; neck short but distinct; stalk very short; skin meven, with ridges; eye very large, open, with projecting scales; color greenish yellow spotted with white; pulp amber, streaked with rose; seeds few but very large. Only the first crop of this variety ripens. It is of the San Pedro tribe. One of the best early figs.

Grosse Grise Bifìre.-Medium, ovate pyriform; neck very short, stalk short; ribs distinct; eye small; skin downy, dark violet amber, pale olive in shade; the bloom is separated by a distinct line from the apex; pulp deep red. A tender, good fig. 
IschIA, BLACK.-Small; neck short; stalk medium; skin smooth; color dark, violet black, greenish around the apex; neck dark; eye medium, open; bloom thin, dark blue; pulp red. Of fair quality but small size.

Ischin, White.-Size below medium, round, with small neck; stalk very short; eye open; skin smooth, bluish green with brown flush; pulp rosy red. Common in California, but hardly worthy of cultivation in that State.

M LGDALEN.-Below medium; round; ribs distinct, rough, disappearing around the eye; stalk longer than the fig; eye open, large; skin greenish yellow; pulp amber white. A very delicious fig, superior to the Ischias and Celeste; not synonymous with Angelique.

MARSEILLAISE, LONG.-Large, longer than wide; skin thick with brownish shade; pulp dull red. Requires moist soils. A fair fig which dries well; not related to either Black or White Marseillaise.

MARSEILLAISE, WHITE.-Medium ovate, pyriform; neck short; stalk medium; ribs numerous and distinct; apex flattened; eye large, open; skin downy, pale yellowish green, mottled with white; pulp amber, with a fer large seeds. One of the best figs for drying. Requires sandy, rich so:l.

Mission, BLACK.-Medium to large, turbinate; neck long; stalk short; ribs distinct; eye prominent, open; skin rough, deep mahogany violet, with a red llush; pulp not fine, red, but not bright or brownish amber; sweet but not high-flavored; common in the Southern States, California, and Mexico. The oldest fig in this country.

Monaco Bianco (syn. White Mlonaco).-Large, ronnded, turbinate, flattened; neck small but very distinct; ribs numerous; eye very open; skin dark, bluish green with thin bloom; pulp dark-red rose; a most excellent fig for table; one of the best in California.

PASTILIERE.-Large, 3 inches by $1 \frac{1}{2}$; elongated, pyriform with long neck; stalk short; eye closed, surrounded by an elevated iris; skin rough, hairy, with blue bloom; pulp red. Fine for preserves.

RONDE NOIRE.-Large, round, but irregular; neck distinct, short; eye small; skin smooth, waxy, dark violet brown; pulp amber. Greatly to be recommended as a table fig. It is not related to Black Ischia or Osborn Prolific.

San Pedro, Black.-Very large, elongated ovate, with no stalk, but with well set neck; skin smooth, violet black with green neck; pulp red, coppery, tinted violet. For table use. The largest fig known. It is not related to the following variety:

SAN Pedro, White (syn. Brebas).-Vory large, round, flattened at apex; stalk and neck short; eye open; skin thick, tender, of a bright yellow color or greenish in the shade, without bloom; pulp amber. A remarkable and haudsome fig. Only the first crop matures without caprification. Suited only for table use. Requires moist, rich soil.

VERDAL, Round.-Below medium, round pyriform, without stalk or 
neck; skin smooth, waxy, bluish green; eye closed; pulp dark, blood red. A small fig, but valuable for canning and preserves; better than the Ischias or Celeste. It does well in the Santa Clara Valley, but is inferior in the interior of the State.

\section{CAPRIFICATION.}

This process must be practiced wherever the Smyrua figs are grown, for without it they will not mature either seeds or figs. The flowers of the Smyrua figs are all pistillate and require pollination, which in the case of these varities can be effected on a large scale only throngh caprification. The process consists in the suspeusion of wild caprifigs, which possess staminate and gall flowers, in the Smyrna fig trees, when the pistils in the blossoms of the latter are in a receptive condition. A minute wasp, the Blastophaga, breeds in the caprifig in large numbers, and on leaving it erawls into the Smyrna fig, covered with the pollen of the caprifig. This pollen, transferred by contact from the body of the wasp to the receptive stigmas of the flowers in the Smyrna figs, effects the fertilization of the ovules of those flowers and causes them to form seeds and mature the fruit of which they are a part. These seeds impart a nutty aroma and flavor to the fig when dried, and give it a marked superiority to our common figs. Caprification is not yet practiced in the United States, the wasp not existing here, though both it and some of the Smyrna figs have been brought to this country several times. The first importation of Smyrna fig trees was made by Gulian P. Rixford, about 1880 , when three varieties of Smyrna figs and a single caprifig tree were introduced.

\section{CLIMATE SUITABLE FOR FIG CULTURE.}

A native of a semitropical climate, the fig requires a similar climate to attain perfection. Many horticultural varieties, however, have originated in temperate regions, and these can be grown with profit in a climate much colder than that of the habitat of the wild fig. Figs, in fact, may be grown in all regions where peaches and apricots succeed withont protection, and if given winter protection they can be profitably grown in such regions near large cities which furnish a market for the fresh fruit at profitable prices.

In considering the suitability of the climate of a region for fig culture, the purpose for which the figs are to be grown must be first determined.

Figs may be grown for drying, for canning and preserving, for sale in the fresh state, or for general home consumption. As the conditions and treatment necessary to produce fruit suited to these different uses vary considerably, each subject will be discussed separately.

FIGS FOR DRYING.

The best dried figs are produced in warm countries, such as the Mediterramean region of Europe, Asia Minor, Upper and Lower Califoruia, but especially in Asia Minor, in the valleys near Smyrna. The 
conditions of climate there are as follows: The days are morterately warm, the temperature seldom exceeding $90^{\circ} \mathrm{F}$. These conditions prevail during the summer, while the figs are growing and ripeniug. The winter is seldom frosty. The winter climate, however, is of less importance, provided it is not cold enough to injure the young figs or the tips of the branches. Such frosts will not injure the second crop, which is used for drying, but it is a great drawback to the wild fig and to the fig iusects, which are necessary to the maturing of the fruit of certain varieties of drying figs. The summer climate is almost rainless, while in winter there are abundant rains. The air in summer is not a dry, desert air, however, but carries considerable moisture. The moisture of the air is an important point, as in a very dry air the figs do not develop high flavor, but are "flat" in taste. During the drying season there should be little or no rain.

\section{FIGS FOR TABLE USE.}

Figs are grown for the table as far north as Paris, in France, and in the south of England.

They may be similarly grown in most of the Middle States of the United States. In England figs are grown against walls as dwarf trees or shrubs, and the trees are covered with mats during the winter. In the vicinity of Paris the trees are dwarfed aud grown as "suckers," which are bent to the ground in winter and covered with several feet of soil. Only certain varieties are suitable for this culture, which, how. ever, is very profitable. The figs produced are all "first crop" figs, and are as a rule of superior quality.

FIGS FOR PRESERVING, CANNING, AND HOME CONSUIPTION.

Except in the most favored localities in the Southern States and California, these are the uses to which American-grown figs must be devoted. To produce fruit suitable for these purposes, freedom from fogs, from summer rains, and from spring frosts is essential. If there is a choice of locality, a warm southern or eastern exposure is to be preferred. The soil should be well drained, never swampy, and the locality should not be exposed to heavy winds. Elevated bottom lands or benches along creeks are the most favorable localities for figs. Large plains, swampy places, or exposed hillsides are all unfavorable. The nearer the conditions approach those of the Smyrna region the better. Rains during the fruiting season are frequently injurious to figs, cansing them to erack aud sour. Still, the fruit may be profitably grown where moderate summer rains occur.

SOIL.

All varieties of figs do not require the same kind of soil. IIost of them, however, must have a rarm, moist, but not wet soil. A very few varieties thrive in a poor, gravelly soil, but most kinds require a deep, 
rich loam, containing a considerable percentage of lime, in order to produce superior figs. A moderate proportion of gravel tends to keep the soil warm and is desirable, but the soil must be rich.

\section{PROPAGATION.}

The fig tree is easily propagated by the methods commonly practiced with fruit trees. It may be budded or grafted, but is most readily grown from enttings. These may be planted where the trees are to stand or rooted in the nursery rows and transplanted later to the orchard site. Which method is advisable for any particular site depends upon the conditions there. If the soil and climatic conditions of the proposed location are favorable to the uninterrupted growth of cuttings, it is better and cheaper to plant them directly in the field. If there is any doubt on these points, or if the proper care and attention can not be given them, the better plan is to plant trees with good roots and wellformed heads, grown under favorable conditions by a nurseryman. The best time for making cuttings is after the leaves have fallen, when the fig tree is comparatively dormant. Cuttings may be made of either one year or two year old wood. If the cuttings are to be planted where they can remain, 2-year-old wood is preferable, as longer cuttings can be secured, but if they are to be planted in nursery, yearling wood is best. In either case the wood when freshly cut should disclose a moist surface, covered with small, whitish, milky drops. If dry when cut, it should be discarded. The leugth of the cutting must be regulated by the condition of the soil. If this is moist and likely to remain so the cuttings may be 12 to 18 inches long. If the surface soil is dry, the cutting should be sufficiently long to have its lower end in moist soil. On very dry soils this may require a cutting 3 or 4 feet in length, though such long cuttings are rarely needed, and in no case except when they are to be planted directly in the orchard. In making the enttings care should be observed that the lower cut be made just below a joint or node and the upper one just above a joint. The best cutting is one which terminates in a bud and has a smooth, clean eut just below a joint at its base. No matter what the length of the cutting, it should always be planted so deeply that but one joint protrudes above the surface of the soil. This will prevent the drying out of the cutting by the action of sun and wind. It is better to have the top bud eovered with earth than to leave a high stump projecting above the surface.

Fig trees may be grown from single eyes or short tips, in boxes filled with moist sand, set in frames and covered with cloth to keep the soil moist and cool. These will make fine trees in time, but they generally require to be a year older than those grown from large cuttings before they are suitable for planting in orchard. Great care should be ezer. cised in removing fig cuttings or plants from one place to another. They dry out readily and a few moments' exposure to the sun or hot, dry wind will seriously damage them. They should never be allowed 
to become dry, and should be wrapped in wet sacks or cloths as soon as taken from the trees or from the propagating bed. Cuttings partially dry may be revived by soaking in water, but fig roots once dry are dead and incapable of restoration to life.

SEEDLINGS.

Seedling figs are easily grown from seeds of imported Smyrna figs. These Smyrna figs always possess germinable seeds, as they have been pollinated. It is quite safe to say that any seedling fig so far recorded in this country has originated from seeds of Smyrua figs imported from Asia Minor. The seeds of our common figs are mere shells without germs, and will of course fail to grow. The percentage of trees producing fruit of high quality among seedlings grown from Smyrna figs is very small, however, and a commercial orchard planted with such seedlings would be a failure. The grower may now and then produce a variety which will repay his efforts, and such variety can be propagated for general planting.

BUDDING AND GRAFTING.

The fig may be propagated by shield budding, provided the work is done at the proper time. That time is winter, when the tree is as near dormant as it can be found. Budding is rarely resorted to, however, as it is an uncertain method when done by persons without skill. Grafting the fig is successfully practiced in California by a method invented by Mr. John Rock. It is the only method of fig grafting that lias proved reliable, practical, and of real value there. By means of it, new varieties are brought into heavy bearing within three years after grafting on old trees. In addition to this saving of time, the usual advantages resulting from grafting, such as better and stronger stock, more vigorous growth, etc., may also be attained.

The best time for grafting the fig is autumn or winter, when the sap is most sluggish. Late spring grafting is less successful. The best scions are made of 2 -year-old wood. The sloping end of the scion must be wedge-shape, tapering from iront to back as well as from the top of the cut to the bottom. But one surface of the wedge should show the pith, and this surface should face toward the center of the stock when the scion is set. Incipient fruit buds should be cut away without injuring the scion. The scion should be so placel that the broad side of the wedge will be outside and the narrow edge toward the center of the stock.

For the stock, any limb from 2 to 4 inches in diameter may be used. This should be cut off squarely at the point to be grafted. A downward cut should then be made with a chisel, in such a way that it shall be tangential to the circular stub. It must not pass through the pith of the stub. The cut should run somewhat obliquely downward and outward, in order that the stock may not be split. The scion, which is 
about 3 or 4 inches long, must, when inserted, form an angle with the long diameter [pith] of the stock branch on which it is grafted.

It is best to place two scions on each branch grafted. These should be on opposite sides of the stub and they should lean slightly toward each other. The exposed surfaces of the stock and scion should then be heavily waxed and the seions should be held in place by binding with cord or other material. It is best to place a large number of scions on one tree. Four or five branches may be cut off and grafted, but one or two should be left uncut for a year to draw the sap. A large stake should be driven into the ground near each branch grafted, and when the scions have started the new growth should be secured to the stakes to prevent them from breaking off. The trunk and main limbs of the fig tree shonld be covered with bundles of straw to pre. vent sumburn. The after-treatment of the new growth is similar to that required in the grafting of other fruit trees. The new growth is strong and rapid and the connection with the stock perfect. Ninety per cent of the grafts may be readily made to grow.

\section{PLANTING.}

The proper distance to be given fig trees in the orchard depends upou the size and habit of the variety to be planted. The smaller kinds require 25 feet; the larger ones should be 50 feet apart in every direction. Sometimes other fruit trees are planted between the figs and allowed to remain until the latter become so large that they require the entire space. The fig tree requires an abundance of air and sunshine to mature its fruit, and it is therefore absolutely necessary that the trees be so arranged that they shall not shade one another. After the distance is decided, the laying out and planting require the same general skill, labor, and methods used in planting other permauent orchards. A few points in planting are peculiar to the fig, however, and require special consideration.

\section{DOUBLE 'I'REES.}

Trees may be set singly, as standards, in the way commonly practiced with other fruit trees, or they may be set "double"-that is, two trees planted together in one hole and allowed to remain. The latter method has not heretofore been advocated in this country but is worthy of thorough trial. The method consists in planting two long enttings, about 12 inches apart, in the same hole, allowing them to protrude from the ground a few inches. Both are allowed to grow and the two are treated as a single tree with two stems or standards. The object sought is to produce two distinct stems or trunks, in order that the splitting down of branches may be prevented. In this way trees with low, sloping branches, having their main trunks leaning outward, will be formed and it will be impossible for the trunks, the main branches, or the 
smaller ones to split down. Branches split only when they point upward or stand straight out-never when they slope downward from the trunk.

\section{STANDARD TREES.}

These may be planted in the usual way, but great care must be taken in shading the roots while the trees are being planted. After they are set, the trunks should be shaded by wrapping them with paper bags or other material, as a sun-burnt tree will never regain its health or bear profitably. Standard trees should only be set for ornament or shade, and even for these purposes the donble trees are preferable. The fig tree naturally brauches near the ground, and the only way to successfully imitate this habit in cultivation is to plant by the double-tree method.

\section{PRUNING.}

The pruning of the fig varies according to the age of the trees and the purpose for which pruning is done. While other fruit trees require yearly, and generally heavy, pruning to insure fruit of good quality, the object in prining the fig is simply, or at least principally, to keep the tree healthy and give air and light to the fruit. The most important rule to be observed in pruning the fig is that no brauch shall be cut off squarely or be cut back so as to leave a stump. This is almost surely fatal to the future welfare of the tree and to the quality and quantity of its fruit. When it becomes necessary to remove a 1-yearold limb the eut should be made at least as far down as the next fork below, and it should be close to a joint in the fork. There should be nothing left but a scar to show that a limb has been cut away. There must be no stump left. The fig tree may require to have its branches thinned ont, but it must not be headed back except to correct unsymmetrical growth. In dense trees branches which cross should be removed entirely and in such a way as to give the tree a rounded, dome-like outline, with the lower branches nearly touching the ground. In pruning recently planted trees the object in view is, of course, entirely different, as fruit can not be expected for several years to come. The object of this early pruning is to shape the tree. When two cuttings are set together little pruning is required, as they will generally shape themselves and form two main trunks diverging from each other, but when a single tree is planted it is best to cut back the stem to within a foot of the soil and let it branch from that point. The only case in which it is proper to have a tall standard is when it is desirable to grow trees for shade aud pleasure and where the quality of the fruit and its quantity are of but secondary importance. If recently planted fig trees show any tendency toward drying out, the main limbs or the whole trunk should at once be cut back to live green wood. 


\section{DRYING AND CURING.}

The drying and curing of figs must necessarily differ in different countries, under different conditions, and for different purposes. For home consumption little skill and care are required to produce a palatable and useful article of diet, while figs intended for shipment must be more carefully dried, cured, and packed in order to command a fair price in competition with the imported article.

The fig is mature and ready to dry only when it has attained its proper size and is palatable for eating fresh. When the crop has reached this stage it may be gathered and dried for home consumption, but in order to produce a superior article the figs must be as sweet as possible and very pulpy. Too often do we find figs in the market consisting of nothing but skin and empty seeds, without sweetness, flavor, or pulp. Figs do not ripen all at one time, and the trees must be gone over daily, in order that only the ripest shall be gathered. Before being picked the fig should be soft to the touch; it should be wrinkled, and should hang downward. Some kinds when ripe show white seams or cracks in the flesh. This is generally a sign of complete maturity. Figs will not ripen after picking and never become sweeter than when cut from the tree. Similarly, figs which have once attained their full maturity do not improve and should be dried at once. If allowed to hang longer on the tree they may quickly rot, sour, or mold, and soon become unfit for use. In order to compete with the best imported figs, our figs intended for drying should be very sweet; in fact, the sweeter the better. When freshly cut they should contain 35 per cent of sugar and when dried about 55 per cent. For home consumption they do not need to be so sweet as this, for any palatable figs are useful when carefully dried.

\section{PICKING.}

Figs to be dried should never be shaken from the trees, for if bruised and injured they will sour during the drying and become unfit for use. A few figs spoiled in this way will check or prevent the sale of a box of fruit that is in other respects good. Pulling the figs from the trees will also injure them in a similar way. The ripe figs should therefore be cut from the tree with a knife or shears and carefully placed in boxes or trays. Of course, many half-dried figs that drop from the trees may be utilized, but they should first be examined to determine whether they are in good condition, and they must be freed from soil and sand. Our figs do not, as a rule, drop at perfect maturity, but either before or after it. Only the Smyrna figs drop when fully ripe.

For the higher growing varieties a convenient instrument called the "fig cutter" may be used. It consists of a forked stick across which has been nailed a strip of tin plate. Below this is a small bag kept open by a wire. With this "cutter" the higher figs may be reached by running the fork up under the fig, severing it from the branch and causing it to drop into the bag below. 


\section{SULPHURING.}

Of late years sulphuring figs before drying has become a very commop practice amoug growers. It consists in exposing fresh fruit to the fumes of burning sulphur in air-tight tray holders of varying sizes. The sulphur fumes cause the figs to become semitransparent when dried, and to present an attractive appearance to the buyer. But nothing is more deceptive, for this very haudsome appearance hides a more than worthless interior, not only detestable to the taste but also injurious to the health of the consumer. Ferw persous will buy such fruit a second time. Besides giving a semitransparent appearance to the fruit, the sulphuring prevents fermentation of the figs while drying. This, of course, is of value, and in fact is the only advantage in the process. A short and light sulphuring may therefore be admissible with varieties which otherwise would not dry and cure without souring.

For convenience, the box in which the figs are to be sulphured should not be more than 5 feet high nor more than 7 or 8 feet wide. This will admit two trays abreast. The trays slide on a rack or on a cleat nailed to the sides of the box, and need not be farther apart than just sufficient to clear each other when charged with a single layer of figs. The door must be air-tight, in order that the sulphur fumes may not escape. Two feet of space should be left between the bottom tray and the sulphur pan. The latter, a heavy piece of sheet iron, is heated, but not to redness, and placed on noncombustible supports in the bottom of the box. Two handfuls of sulphur are thrown upon this iron and when it is burning the doors are tightly closed. Exposure to the sulphur fumes for fifteen minutes is sufficent to prevent fermentation during the drying process and leave the figs with a minimum of sour taste. If sulphured longer they become too acid. After removal from the box the figs should be immediately exposed to the sun. Black figs should never be sulphured.

\section{DIPPING FRESH FIGS.}

Instead of being sulphured to improve their color and soften their skins, figs may be dipped into a hot solution of salt or saltpeter, or even lye. Unless, however, they are immersed for a long time this dipping will rarely prevent fermentation, though it will prove advantageous in other ways. Figs with a rough and tough skin are especially benefited, the principal effect of the dipping being to soften the skin. But this dipping should be practiced only on figs of inferior quality, the best grades not being improved either by dipping or sulphuring.

In dipping, the figs should first be placed in a perforated bucket and rinsed in cold water, to free them from dust. They should then be transferred to a kettle containing boiling lye, made of 1 pound of potash to 10 gallons of water. An immersion of from one-fourth minute to one minute suffices; the time being regulated according to the size of the figs and the pliability and thickness of the skin. Boiling salt water 12417-No. 5-2 
may be substituted for the lye water for the dipping of some figs, different varieties requiring different solutions to secure the desired result. After dipping, the figs are dried without rinsing. If salt or saltpeter is used instead of lye, $1 \frac{1}{2}$ pounds of either to 50 gallons of water is a proper quautity. Lye is generally used, but the writer prefers salt or saltpeter, either of which gives good results as regards pliability of skin, while the salty taste generally improves the flavor.

\section{DRYING ON TRAYS.}

For convenience in handling, wooden or paper trays are commouly used for drying figs in the Western States. By their use the fruit can easily be stacked and sheltered in wet weather. The trays are of various sizes, but a small size, such as $2 \frac{1}{2}$ feet by $3 \frac{1}{2}$ feet, or $3 \frac{1}{2}$ feet by 4 feet, is preferable, as when filled with fruit it can easily be haudled by one man, while a larger size requires two men. The drying ground should be a clean space outside the orchard, where the trays may be exposed to the minterrupted rays of the sun. The figs require all the sunshine obtainable, and the drying ground must therefore be free from the shade of trees or buildings. The drying floor may consist simply of beds of soil elevated a foot above the general level. A drying floor 4 feet wide may be raised $S$ inches additionally along one side. The slope toward the sum thus given will insure greater heat. Trays may be placed on strips of wood or scantlings supported by low sawhorses. The sawhorses should be long enough to support two rows of trays abreast. Three scantlings or strips will be required for each pair of sawhorses. They should be of even lengths, as long as obtainable, and the middle one should be larger than the outside ones; 2 by 4 inches for the middle one and 2 by 3 inches for the side scantlings will be found convenient sizes. The figs should be placed singly on the tray, with their eyes all toward one side, and this side of the tray should be slightly raised in order to prevent the contents of very juicy figs from running out during the process of drying. The raising of the trays is the most easily accomplished by placing the 2 by 4 inch supporting strip in the middle of the sawhorses and the 2 by 3 inch strips on either side. Immediately after sulphuring, if that is practiced, or after dipping, the fruit should be spread and the trays distributed on the racks where they will have the full benefit of the hottest sun. This distribution of the trays should be finished before noon each day to secure the best color of the dried product.

The figs must be turned twice a day at first and once a day in the later stages of drying. The turning requires much work and expense, as it can be done well only by hand labor. An inferior product may be turned by placing an empty tray face downward upon a filled one and inverting them, leaving the fruit on the new tray. To produce the best grade of dried fruit, the figs should not touch one another on the trays during the process of drying. During the turning, all inferior figs, 
such as those that ferment and puff up, should be culled out and used for vinegar. Figs which show a slight froth at the eye are turning sour and should be removed.

Covering the figs must not be neglected, if a choice article of dried fruit is to be produced. If white figs are left out over night uncovered, they will be discolored. Rain and dew are very damaging and the fruit should be protected from them. This is best accomplished, in California, by stacking the trays one on top of another when rain is expected. The top and sides of the stacks should then be protected with empty trays. If permanent drying beds of gravel and cement are made, a mechanical device for covering the trays with a horizontal canvas curtain can be used, and in this way they can easily be covered every night.

\section{DEGREE OF DRYNESS.}

It is very important that drying cease when the figs have reached the proper stage for packing. They must on no account be overdried nor should they be removed from the trays too soon. The proper degree of dryness can be detected by pressing the figs between the thumb and finger. They should be soft and pliable, with the contents distinctly pulpy, and when squeezed the fig should not resume its former shape, but remain pressed. It should be plastic, not elastic nor dry. Underdried figs will spoil in packing, while overdried ones are hard, leathery, and worthless as food or delicacy. The trays must be goue over every day and the properly dried figs taken off, the spoiled ones being removed at the same time. The time required for drying varies from four to sixteeu days. Drying within six or seven days yields the best quality of product.

\section{SWEATING AND EQUALIZING.}

Dried figs are greatly benefited by being sweated or equalized as regards moisture. This is accomplished by placing them in sweat boxes holding 75 pounds or more. The boxes are stacked up one across another in such a way as to insure a free circulation of air. This is to prevent the sour fermentation, which would spoil the figs. The room where the sweat boxes are stored should be closed and the walls should preferably be of brick. Daily examination of the contents of the boxes should be made, so that any inclination of the fruit to ferment and heat may be detected. In a few days an improvement in the texture of the figs will be noticed, the overdried ones having attracted moisture from those that were underdried and all having become more pliable.

\section{ARTIFICIAL DRYING.}

Where figs can not be dried in the open air, evaporators or driers, heated artificially, may be used to advantage, just as in the drying and curing of raisins. Large driers are expensive and are beyond the reach of many growers, but small driers, holding a ton of fruit, may be built 
cheaply. It may be safely stated, however, that localities where artificial drying is necessary are not suited to the most profitable production of commercial figs, as any extra handling will greatly increase the cost of the product. Where a very superior article is produced the occasional use of the drier may be profitable, in order to save a crop that would otherwise be injured by inclement weather.

\section{PACKING.}

The method of packing dried figs and the kind of package used should vary according to the quality of the finished product. They should be packed in order to prevent drying out, as well as to make them present an attractive appearance. It pays to pack the best grades well, for good packing always enhances the value of fruit.

\section{DIPPING.}

The first step in packing is the dipping of the dried fruit, and this must be done whether the figs are packed cheaply or expensively. The dipping, which must be done just before packing, causes the figs to become soft and pliable, equalizes moisture, and improves the skin and its color. Perforated buckets holding 5 gallons of dried figs are suitable vessels for holding the figs during the dipping. A kettle arranged for heating water and large enough to permit the immersion of the bucket of figs should be provided. In this kettle sea water or brine made of one-fourth pound of coarse salt to a gallon of water should be heated to the boiling point. The bucket of figs should then be immersed in this boiling brine for a few seconds and emptied on to wire screens to drain. While draining, the tigs should be covered with a cloth or otherwise kept dark. The fruit should be packed on the same day that it is dipped. The best grade of white figs, or very soft figs of any grade, should ouly be dipped in cold salt water, just before packing. The salt water is never washed off, and the salt that remains does not in the least injure the figs, but, on the contrary, improves their quality.

\section{ASSORTING,}

The inferior figs which were removed from the trays during the drying process should be assorted into at least two sizes for packing. A yet lower grade which ean not be profitably packed may be sold in sacks. The largest Smyrna figs weigh, when dried, about 23 grams [355 grains, or about four-fifths of an ounce avoirdupois], while the average French and Italian figs weigh each about 8 grams [123.45 grains, or a little more than one-fourth of an ounce avoirdupois].

\section{PULLING.}

The best grades of figs should be pulled or flattened before packing. This pulling consists first in squeezing the fig with the hand to soften it, and then flattening it so as to shape it into a disk in which the eye 
and stalk are nearly in the center of the flat sides, as may be observed in packages of figs imported from Smyrna. The object of this pulling is to have the figs present as fine a surface as possible when they are pressed and packed, this method enabling the packer to hide the eye and stalk ends effectually. For inferior brands it will suffice to simply flatten the figs in such a way that the eye and stalk are at opposite extremities of the fruit when pressed. In pulling and handling the figs, the hands of the worker should always be moistened with salt water to prevent them from becoming sticky with sirup and thus soiling the figs.

PACKING.

The packing should be regulated according to the size and quality of the figs. The size of the boxes will therefore vary, but they may be made to contain 5, 10, or 20 pounds each. In Smyrna the figs are packed in the shape of bars, and this method should be followed for all the better grades. In order to pack quickly in bar fushion, the writer several years ago invented a "bar-packing device" or "guide." This guide consists of a frame of two or three parallel strips of tin or zine connected at opposite ends by two similar strips. The guide, which is really a metal box without top or bottom, fits exactly into the packing box flush against two of the sides, but is slightly higher than the depth of the box in order that it may be pulled out after filling. The guide is placed in an empty fig box, thus dividing it into three or more compartments. The figs are then placed in rows in each compartment with the eyes dowuward, each fig slightly overlapping the other, in the way shingles are laid on a roof, just sufficiently to hide the atalks. The compartments in the guide should be slightly narrower, or at most no wider than the figs, so that when pressure is applied the figs will flatteu and fill them. The object of the guide is to keep the fig bars separate. After the box is full a slight pressure is applied, which squeeres the figs against the sides of the guide, and when the latter is withdrawn leaves the bars intact without large air holes between the figs or bars.

\section{PRESSING.}

The raisin presses used in California are suitable for pressing figs. There is no better machine for this purpose made anywhere. A follower of wood covered with zine is first placed in each compartment on the figs and a slight pressure applied in the press. The pressure must be strong enongh to bring the figs to the level of the box. The guide is then lifted ont, while the fingers of the packer press firmly on the follower to hold the figs in place. Instead of having a guide in which the bars are connected at the ends, the box may be groover on the inside and a single strip of zine or tin dropped down, thus dividing the box into two or more compartments as may be necessary. The strips are more easily removed than the more complicated guide. Before the box 
is nailed up, small leaves of the sweet bay (Laurus notilis) should be inserted between the figs on the surface, and over the whole should be spread a sheet of waxed paper. Instead of the sweet bay leaves, other native laurel leaves may be used, provided they are aromatic, have the distinctive laurel flavor, and are not otherwise objectionable.

It can not be too strongly urged that American-grown figs be packed and sold under their proper labels and not designated "Smyrna" figs. Careful selection of varieties, skill in growing and curing, and careful, honest packing will in time procure a large market for our figs.

In all the Mediterranean countries the fresh as well as the dried fig is a common article of diet, both nourishing and wholesome, and it is only a question of time when its value will be generally recoguized in this country. 


\section{FIG CULTURE IN THE GULF STATES.}

By Frani S. Earle.

The fig is a domestic fruit of prime importance in all the Gulf and South Atlantic States; throughout this region it is a common dooryard tree. Its broad, rich foliage is one of the first things to catch the eye of the Northern visitor and assure him that he is really in the South.

Toward its northern limit the tree is sometimes injured by unusually severe winters, but unless killed to the ground it never fails to produce heavy annual crops. Even severe winter-killing is usually but a temporary loss, as the roots send up vigorous sprouts that bear the following year.

Although the fig is so widely distributed and so universally esteemed for household uses, it is only recently that any attempt has been made in the territory under consideration to utilize it as a commercial product. In the search throughout the South for possible money crops, other than cotton, it is beginning to attract attention, and in this connection a brief statement of our present knowledge as to the growth and possible uses of the fig may be of service.

\section{PROPAGA'TION.}

The fig roots easily from cuttings and is usually propagated in this way. Short pieces or even large branches of well-matured wood, cut from the tree at any time during the winter aud simply thrust into the soil, will usually take root and make a strong growth the following summer. The well-matured wood is best for making cuttings. One of the most desirable methods is to cut a section bearing a short but thrifty lateral branch from a good-sized limb. The section taken should be 6 or 8 inches long and be entirely buried in the ground, leaving the end of the side branch projecting to form the tree. This is not at all essential, as a straight cutting will usually root and grow readily, but it is desirable, as the buried cross section holds the cutting firmly in the ground and its bulk prevents it from drying ont easily. In the coast region euttings are often planted in August with good results. In this case the leaves slould be removed. It is advisable to plant the cutting where the tree is to stand, as fig roots are easily injured by transplanting. Little is gained in grow th by planting rooted trees, but when such are used both roots and tops should be heavily pruned when planted, to secure a satisfactory growth. 
Sometimes it is advisable to plant the cuttings in the nursery and to keep them there for three years before removing them to their permanent location, as winter protection can be more easily given them. After the trunk of the fig is three years old it is much less easily injured by cold. This practice would seem to be of doubtful value, since young figs are more often injured by late frosts after growth has started in the spring than by the greater cold of midwinter when they are dormant. Figs can be grafted without diffienlty, but it is seldom done in the south.

\section{SOIL AND LOCATION.}

The fig will grow in almost any location, but it attains its highest development on a rich, moist, but well-drained soil, that contains abundant humus.

A plentiful supply of lime, phosphoric acid, and potash is also needed, and if not contained in the soil must be supplied by fertilization. The best conditions for fig growth are found in the bottoms and hammocks rather than in the sandy uplands, though many fine specimens can be found in either location. In planting for home use it is advisable to plant the trees near the house and about the farm buildings, for they always thrive in such locations, while many failures have been made in attempting to establish them under orchard conditions, especially in the light soils of the "piney woods" region. It is not easy to account for these failures, since the old dooryard trees are so universally healthy and thrifty, though growing without eare or attention. Several causes can be cited that may contribute to the result, but all seem insufficient to account fully for the facts observerl. There must be some undetected factor that contributes to the almost universal superiority of dooryard over orchard-grown fig trees in the Gulf States.

One of the most obvious difficulties in establishing a fig orchard arises from the fact that the young trees are tender and easily injured by the cold. Figs start very early in the season, and the frequently occurring spring frosts often catch them in quite vigorous growth. This does no great harm to old trees; though the young leaves are killed, they soon push out again, and as the principal crop of fruit is borne on the new wood the crop is not much injured. With young trees, however, it is different, as the tissues of the trunk are softer. Fine, thrifty trees of one or two years' growth are killed to the ground by a slight freeze after their spring growth has started. They may start again from the root, but their vitality is injured and they do not seem to fully recover. Such trees at 3 or 4 years old are often no larger than after the first summer's growth. Young trees also suffer much more severely than old ones from extreme cold in winter, even when entirely dormant. It would appear that the shelter afforded by buildings and yard fences may sufficiently protect young trees from damage, when in an open space they would be severely injured. Then, if from a dozen cuttings stuck down in such out-of-the-way places only two or three 
grow, they are seen and remembered, while the failures are forgotten, whereas an orchard row showing a stand of only one-fourth is very unsatisfactory. The dooryard tree usually gets the benefit of ashes and house-slops, and perhaps the wash from the barnyard. These sources of fertility are all beneficial, for the fig is a gross feeder. Its roots are never broken by the plow, which is another great advantage, for the fig has a shallow rooting habit and does not thrive when its feeding roots are disturbed.

In the light soils of the South it is extremely difficult to keep plows and cultivators from running so deep as to do serious injury to fig trees, and the proper cultivation or treatment of a fig orchard is therefore a serious question. Many growers advise against plowing after the first year, but the tree will not thrive if choked with grass and weeds. To keep a large orchard clean with a hoe is no small undertaking. Some advocate heavy mulching to keep down weeds, and that is doubtless often advisable, but the hard, clean-swept southern dooryard seems to suit the root habit of the fig better than any system of cultivation yet devised. Another point to be considered is that the fig suffers severely from root knot when planted in the fields where vegetables or cowpeas have been grown, as the nematodes'causing this trouble multiply in the roots of all such crops.

In planting a fig orchard care should be taken to select new land that is known to be free from these pests.

The fig has a spreading habit of growth and when old requires considerable room. As the cuttings cost but little, it is well to plant rather closely, with the expectation of thinning out the trees when neccessary. With 200 trees to the acre the earlier crops would be double those obtained from a planting of half that number, though doubtless 100 full-grown trees would sufficiently occupy the land. Twelve by 16 is a suitable distance for the trees when young. Removing alternate rows when needed. would leave the permanent planting 16 by 24 feet. It is best to plant two or tiree cuttings at each place, to be sure of a stand. All but the most vigorous ean be eut out if more than one starts to grow.

\section{CULTIVATION AND FERTILIZATION.}

Unquestionably figs should be thoroughly cultivated during the first season. This is necessary to give them a good start, and as the young trees make their largest growth after midsummer it is important to continue the cultivation late in the season. Unless the soil is quite rich some fertilizer should be used, as the future of the tree depends iargely on its vigor during the first season. An excessive use of stable manure or other nitrogenous fertilizer should be avoided, as the tendency of these is to induce a soft, succulent growth too easily injured by the winter. The "piny-woods" soils are deficient in phosphoric acid, aud this should be a prominent ingredient of all fertilizers used in regions where these predominate. 
It is not advisable to attempt to cultivate any vegetable crop among fig trees, on account of the danger of increasing root knot, and because such crops are likely to interfere with cultivation at the time when it may be most needed.

The best subsequent treatment for a fig orchard is, to a certain extent, an open question. It is probable that in most locations the best results will be obtained by mulching heavily near the tree with any available material that will hold moisture and keep down the weeds. Pine straw, marsh grass, or planer shavings answer the purpose. The dust from old charcoal pits is sometimes used, and on the coast a mulch of oyster shells is often seen. The slowly decomposing shells probably act to some extent as a fertilizer, since the fig is known to thrive best in strong lime soils. The middle of the rows can be kept clean by a shallow plowing and harrowing without disturbing the mulch and without injury to the roots protected by it. Winter protection of some kind should certainly be provided during the first two or three years, at least to the extent of mounding the dirt or mulch high about the base of the tree in the fall. Protecting the tops with old gunny sacks or pine branches will often prove of great advantage.

Pruning is seldom practiced, except so far as may be necessary to properly shape the young tree, and this is better done in summer by pinching. In case of a freeze, all injured wood should be promptly cut away. It is said that the size of the fruit can be greatly increased by judicious pruning, but, as before stated, it is seldom done.

Figs come into bearing very early. A thrifty growing cutting will often set some fruit the first season, but this seldom matures. When the tree does not winterkill, a little fruit may be expected the second season, and by the third the crop should be of some importance.

\section{INSECT ENEMIES AND DISEASES.}

The fig is usually spoken of as being comparatively free from insect enemies, and the literature of its diseases, of which there are a number, is scanty. It is probably true that in most localities it is less frequently injured from these causes than are other fruit trees.

Among the diseases reported from the South the one causing most widespread injury is doubtless root knot.

FIG-TREE BORER.

A longicorn beetle, Ptychodes vittatus, has caused considerable injury at some points in Lonisiana and Mississippi by burrowing into the trunk and larger branches. In reply to inquiries regarding this insect, Director W. C. Stubbs, of the Louisiana Experiment Station, says:

The damage done in Lonisiana is to a large extent eonjectural. In our groves we have lost several trees temporarily, all being bored into by this borer. They, however, start up again quickly from the roots and soon replace the injured trees. We have had no remedy against this invasion except to dig it ont while very young with a penknife. We have tried various insecticides withont any apparent results. 
FIG-LEAF MITE.

A browning and subsequent premature falling of the leaves, caused by the work of a minute mite, is reported as rather common in Florida by Mr. H. J. Webber, of the Subtropical Laboratory. It has not been studied.

Mr. Ellison A. Smith, jr., botanist and entomologist of South Carolina Experiment Station, has published a list ${ }^{1}$ of insects observed feeding on ripe figs, but he does not mention any that injure the tree.

ROOT KNOT.

This disease is caused by a microscopic nematode or true worm, Heterodera radicola, ${ }^{2}$ that infests the soft fibrous roots causing small galls or swellings. When present in sufficient numbers it causes the death of the roots and the consequent starvation and death of the tree. It is by no means confined to the fig, but attacks the roots of many other fruit and ornamental trees and shrubs and is especially injurious to many garden vegetables and farm erops. ${ }^{3}$ This pest thrives best in moist sandy soils, and is troublesome throughout the entire coast region.

No effective remedy is known when a tree is once infested, hence the necessity for planting on land known to be free from the pest, and the importance of not growing vegetables between the trees that will act as a nurse crop for the disease.

Neal recommends thorough drainage of the land and tle application of tobacco dust mixed with unleached ashes or lime as the most promising remedial measures. He advises against the excessive use of ammoniacal manures as producing a soft, succulent root growth favorable to the growth of the nematode. (See Bulletin No. 20, previously cited.)

FIG-LEAF RUST.

Brown spots frequently appear on the foliage during the summer, and, if numerous, cause the leaves to fall prematurely. These spots are caused by a true rust fungus, Uredo fici Cast. It occurs quite frequently widely, and abundantly, but as it usually does not develop enough to be noticeable until aiter the crop is ripe, it seems to do but little harm. No attempt has been made to find a remedy.

FIG CEIRCOSPORA.

A somewhat similar injury to the leaves is known in Europe, caused by an entirely different fungus, Cercospora bollean (Thum) Sace. It had not been observed in this country until the summer of 1895 , when

${ }^{1}$ South Carolina Experiment Station, Annual Report, 1889, pp. 105, 106. The list is as follows: Allorhina uitida (L.), Ptychodes trilineatus, Lybithea bachmami (Kirth), Apatura celtidis (Bd. Sec.), Grapta interrogationis (F.), Pyrameis atalanta (L.).

${ }^{2}$ G. F. Atkinson, "A proliminary report upon the life history and motamorphoses of a root-gall nematode (Heterodera radicola (Greefi') Miill.) and the injuries caused by it upon roots of various plants."-Alabama Agr. Exp. Sta. Bul. No. 9.

${ }^{3} \mathrm{~J} . \mathrm{C}$. Neal, in an account of the root-knot diseaso (Dept. Agr., Div. Ent., Bul. No. 20) gives a list of over 60 species of plants known to be infested by it. 
it was found abundantly in Mississippi by S. M. Tracy. A cercospora, probably the same species, is also reported from Florida by Н. J. Webber. It probably occurs quite commonly, but has been overlooked, its injuries being confounded with those caused by the Uredo.

DIE BACK.

A dying of the young shoots in the fall and early winter is sometimes noticed. This occurs before they can have been injured by severe cold and its cause is not known. It usually occurs in feeble trees, those injured by previous winter killing or perhaps those suffering from root knot. A similar trouble is noted by A. F. Barron, of Chiswick, England, (The Garden, June 20,1891,p.577). He finds it occurring in trees grown in pots, and says it is there seldom noticed in trees growing out of doors.

ROOT ROT,

The fungus Ozonium auricomum Lk., which causes a root rot of cottou and of many other plants and trees, has been reported upon the fig, ${ }^{1}$ but the extent of damage eaused by it is not known. Several other species of fungi are known to occur on the fig, but none of them can be classed as disease-producing organisms.

VARIETIES.

Much confusion exists in the naming of fig varieties. They were first introduced by the early French and Spanish settlers, and there have been more or less frequent importations since. Trees from these various sources have been known under many local names, and it is probable that there are now many more names recorded than we have varieties in cultivation. On the other hand, distinct varieties are often met with that can not be named from published descriptions. In Louisiana and Mississippi it is safe to say that nine-tenths of all the figs grown are of the Celeste variety. This is sometimes written Celestial, but among growers it is uniformly known as Celeste. The tree is hardy and very fruitful. The fruit is small, but it is one of the best in quality. When ripe it is a light yellowish brown, tinged with violet. The flesh is light red, delicate in texture, and very sweet and rich. A number of other varieties occur, but they are known under local names, such as "black fig" or "Spanish fig." More attention has been paid to nomenclature and to the planting of different varieties in other parts of the South, but the Celeste is the favorite in nearly all localities.

Some interesting papers on figs were read at the meeting of the American Pomological Society, held in Florida in 1889, and in the published proceedings of the meeting the following 18 varieties are catalogned among the fruits recommended by the society.

'Farlow and Seymour, A Provisional Host-Index of the Fungi of the United States, Part 3, p. 183. 
List of figs recommended by American Pomological Society.

Alicante; Angelique-synonym, Jaune Hative; Brunswick; Blue Genoa; Black Ischia; Brown Smyrna; Celeste; Green Ischia-synonyms, White Ischia, Green Italian; Lemon; Violet, Long; Violet, Round; Nerii; Pregussata; White Adriatic; White Marseillaise; White Genoa; Superfine de la Sausaye; Turkey-synonym, Broun Turkey.

On comparing this list with 11 others furnished by nurserymen and writers on the fig, and taken at random from Texas, Louisiana, Georgia, and Florida sources, we find 14 of these names occurring more or less frequently. Four are not mentioned at all, while 13 additional names appear, making a total of 31 varieties in the 12 lists. Celeste and Brown Turkey lead, being mentioned 11 times each; Adriatic, Lemon, and Brunswick come next, each occurring 8 times. White Marseillaise is mentioned 7 times; White Genoa and Green Ischia, 6 times; Black Ischia, 5 times; and San Pedro, which is not in the American Pomological Society's list, occurs 4 times. We may perhaps conclude that these 10 varieties are the most generally grown in the South, but some of them are to be considered as nurserymen's recent introductions from California, rather than as varieties in general use. They are characterized in the Pomological Society's list as follows:

\begin{tabular}{|c|c|c|c|c|}
\hline Variety. & Season. & Color. & Quality. & Size. \\
\hline
\end{tabular}

Other lists agree in describing both White Adriatic and San Pedro as very large white figs of the best quality and very desirable where they succed, but as being tender and nonfruitful in many locations. Celeste, Brown Turkey, and Brunswick are more uniformly commended for hardiness, fruitfulness, and general utility than any others. ${ }^{1}$

\section{USES.}

At present figs are mostly used for household purposes, comparatively few being prepared for market. They are eaten fresh from the tree or are served on the table with sugar and cream. They can also be stewed and made into puddings and pies, and when canned or preserved they make an acceptable table delicacy throughout the year. On first tasting fresh figs many people are disappointed and think they will not care for them, but on further acquaintance nearly everyone learns to

${ }^{\perp}$ The canning factories greatly prefer the Celeste, paying one-fourth more for them than for larger, coarser kinds. 
like them. If picked at all green the fig exudes a milky, acrid juice that has a rank, disagreeable flavor. When fully ripe this disappears, and in learning to eat figs one should choose only the ripest specimens. The beginner will find eating them at the table with plenty of sugar and cream a pleasant introduction. It is needless to commend this method to those who are acquainted with it.

For canning, figs should be picked when still firm enough to hold their shape. To secure the best results they require the use of more sugar than do some other fruits. If undersweetened they seem tasteless and lacking in quality. The amount of sugar used and the method of procedure vary greatly in different households. A pound of sugar to 3 or 4 pounds of fruit would probably suit most tastes, though some prefer the regular "pound for pound" preserve. Ginger root or orange peel is sometimes added to give variety of flavoring, and figs are often made into sweet pickles by adding spices and vinegar. Figs are sometimes peeled before canning, and this is considered to increase their delicacy of flavor. More frequently, however, they are cooked unpeeled and with the stems on, just as they come from the tree. They hold their shape better and look more attractive when treated in this way, and the difference in flavor, if any, is very slight.

Figs are occasionally dried for household use, but as they ripen at the South during the season of frequent summer showers, this is so troublesome that it is not often attempterl. A nice product could doubtless be made by use of fruit evaporators, but these are seldom used far Sonth.

In speaking of home uses for the fig, its value as food for pigs and chickens should not be forgotten. Both are very fond of them, and on many places the waste figs form an important item of their midsummer diet. In fact, no cheaper food can be grown for them.

\section{MARKETING FRESH FIGS.}

Ripe figs are very perishable. To be marketed successfully they must be handled with great eare. It is best to pick them in the morning, while still cool. They should be taken from the tree with the stem attached-great care being exercised not to bruise them in handlingand placed in small, shallow baskets, in which they are to be marketed. In large packages their weight will bruise them badly. The ordinary quart strawberry basket crate is a suitable package for marketing figs. They will carry better, however, in flat trays, holding but a single layer. This form of package is especially desirable for the larger varieties. Figs should hang on the tree until quite ripe and develop their full sweetness and flavor, but in this condition they are soft and perishable and must be consumed at once. For marketing at a distance it is necessary to pick them while still quite firm. This is unfortunate, for though they will soften and become quite edible, they will lack the fine quality of tree-ripened fruit. This fact will always be an obstacle to the successful introduction of the fresh fig into distant markets. When 
picked in right condition the fruit will keep from trenty-four to thirtysix hours at the ordinary temperature and may be shipped short distances by express. Figs ripen in midsummer when the weather is hottest, and this is one reason why they are so difficult to handle. Like other fruits they will keep longer at lower temperatures. They do well under refrigeration, and by using refrigerator cars it is quite possible to put them on the more distant Northern markets in good condition. This has been done experimentally in connection with other fruit shipments, but it is not often attempted. Fresh figs are not known or appreciated in Northern markets, and consequently the demand is too limited to encourage shipments. It seems doubtful if the distant shipment of fresh figs will ever become a profitable business. The fruit is more perishable than any other that is generally marketed. It can be handled only by the most careful and experienced persons, and even then it is not in a condition to show its best quality. Ripening in midsummer, when the Northern markets are crowded with many well-known fruits, and not being specially attractive to the eye, fresh figs would at best gain favor slowly. The fact that many people do not care for them at the first would be another obstacle in the way of their popularity. Moreover, the fig is a tedious crop to handle, when in proper condition for market. It is necessary to pick the trees over carefully every day during the season, or much fruit will be overripe. With large trees, this involves much labor; the acrid juice of the immature figs eats into the fingers of the pickers and packers, while rainy weather occasions heavy loss by the eracking of the fruit, which reuders it unfit for market.

Notwithstanding these drawbacks, a limited demand would undoubtedly be created if the fig were placed regularly on the market, for many people are very fond of this fruit. It is quite possible that in sectious especially adapted to fig culture, and favored with rapid refrigerator transportation, the shipment may become a business of importance. When a regular home market can be found, even at moderate prices, no crop is more profitable, as the trees bear regularly and abuudantly. The only hope for such a home inarket, except in the immediate neighborhood of large cities, is in increased use by canners.

\section{CANNING FACTORIES.}

Everyone likes canned figs. The taste does not have to be educated, as is often the case with the fresh fruit. The factories at Biloxi, Miss., and at New Orleans, La., appreciate this fact, and for several years have been putting increasing quantities of the canned product on the market. $\mathrm{Up}$ to the panic of 1893 the demand for these goods was very active, and the canners paid as high as 4 cents per pound for the fresh figs and could not get enough to fill their orders. Since then the demand for all luxuries has fallen off and factories have curtailed their packing, but have not materially reduced the price of the product, which has alrways been very high. There seems to be no reason, aside from 
the larger quantity of sugar required, why figs should not be grown and canned as cheaply as peaches. If this were done the demand would soon be very large. It is in this direction, if at all, that there seems to be an opening for the building up of the fig industry in the South.

The processes used by the factories in canning figs differ somewhat from household methods. They also differ amoug themselves. Each factory has worked out a plan of its own, the details of which are regarded to some extent as trade secrets. In one factory, whose product has been much admired, the process consists in boiling the fruit at first in a very light sirup, allowing it to cool, and then transferring it with successive heatings and coolings to sirups of gradually increasing density. The whole process requires nearly two days. In the finished product the fig, while holding its shape perfectly, has become partially transparent, and as the final sirup is clear and free from sediment the fruit is very attractive. 





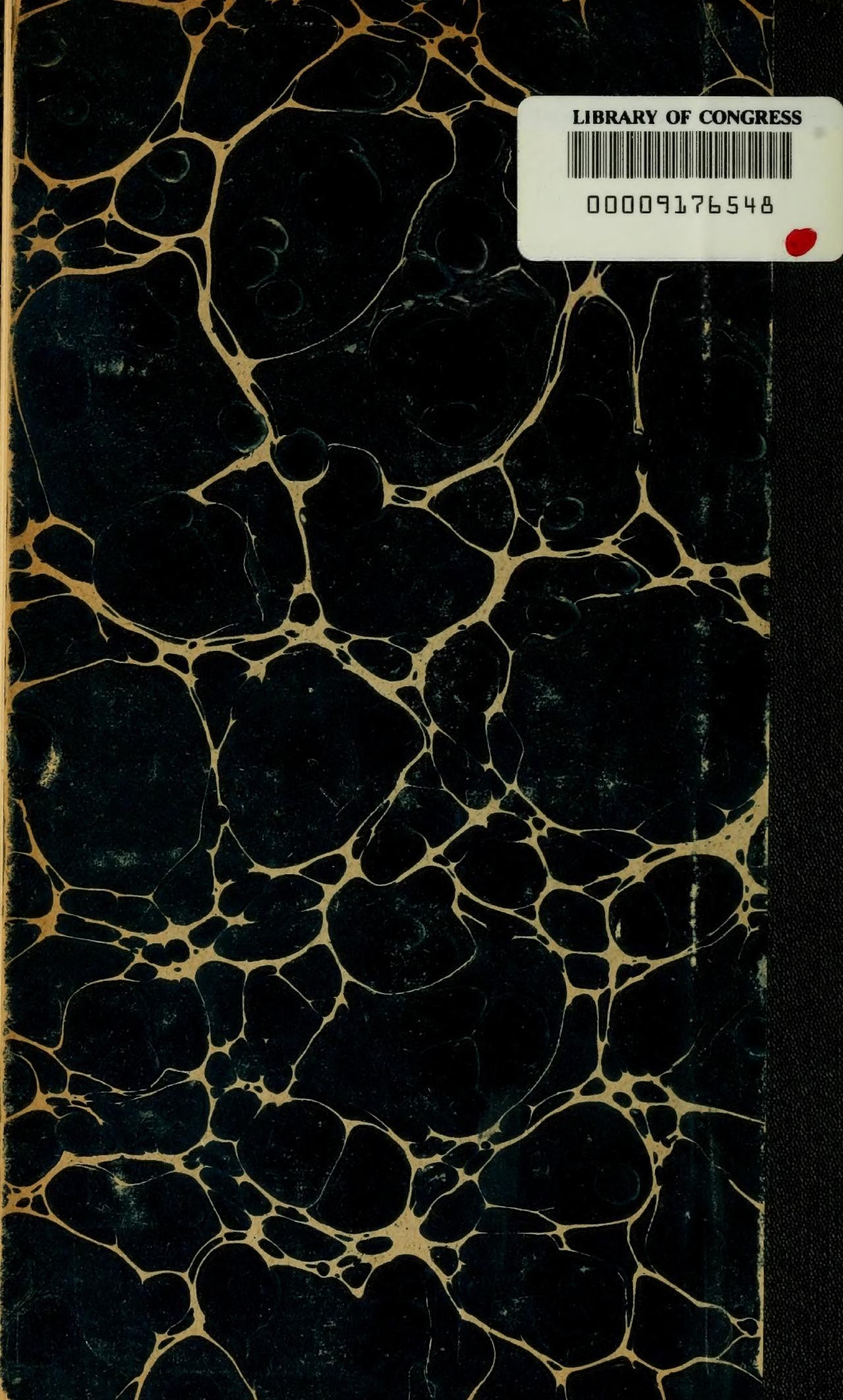

